\title{
Application of technical and economic evaluation in construction projects
}

\author{
(Xi'an Changqing science and Technology Engineering Co., Ltd., Shaanxi, Xi'an 710018, China )
}

Construction industry is one of the pillar industries in China's economic growth and an important force in the development of the national economy. But for now, the construction project management and economic benefits are to be further strengthened, especially the costs and benefits of other economic indicators need to be strengthened, and lay a solid foundation for creating greater economic benefits. In order to do this, it is necessary to strengthen the technical and economic evaluation of construction projects. In the construction project implementation process of technical and economic evaluation, can strengthen the project cost control, make the project cost and construction quality coordination, expand profit space, for enterprises to create huge profits.

1. The definition, connotation, method and significance of economic evaluation of construction projects

\section{1 definition}

Economic evaluation is a combination of technology and economy. It is mainly used to analyze the input costs and possible benefits of engineering projects, and to analyze the economic feasibility[1]. It is a part of the feasibility analysis of the construction project. It is based on the principles of economics and engineering, and is analyzed by means of system analysis, quantitative analysis and qualitative analysis.

\section{2 connotation}

Construction project duration is generally longer, more capital investment, inevitably there is a certain investment risk. In order to understand the investment risk more accurately and the feasibility of the project investment, the technical and economic evaluation must be carried out Technical and economic evaluation of construction project the main objective is to reveal the economic and technical characteristics of the construction project, providing basis for investment decision-making, maximize resources, make the resources be used reasonably, and create a good economic effect.

\section{3 methods}

The technical and economic evaluation methods of construction projects mainly include static analysis method and dynamic analysis method. Among them, the static analysis method has the

\begin{abstract}
Technical and economic evaluation is the main means of construction project cost management, risk management and project schedule control. It is widely used in investment decision-making, design and construction phase of construction projects. Based on a large number of documents, this paper first analyzes the definition, connotation, methods and significance of technical and economic evaluation of construction projects. Then, starting with the technical characteristics of construction projects, combined with the previous work experience, the construction engineering project technical and economic evaluation of the application of a brief analysis, for reference purposes only.
\end{abstract}

Key words:Construction Engineering; technical and economic evaluation; connotation; technical characteristics

Published on 30th Sept,2017 
payback period method, such as Formula 1; dynamic analysis has the net present value method, and its expression formula such as formula 2 .

Formula 1: $\sum_{t=0}^{P_{t}}(C I-C O)_{t}=0$

Formula

2:NPV $=\sum_{t=0}^{n} \frac{(C I-C O)_{t}}{(1+i)_{t}}$

\section{4 significance}

We can see from the definition, technical and economic evaluation of construction project of the connotation, its greatest significance lies in reducing the construction project investment risk, have great positive significance to implement programs, project cost management, project progress control of the project. It can not only reduce the failure rate of investment decision-making, but also reduce the cost of the project and create more profit space for the enterprise.

\section{2. technical and economic characteristics of construction projects}

Building engineering including internal structure, external modeling and interior decoration, hydropower and other parts, is different from traditional products. As is known to all, the function of building products determines its technical and economic characteristics. From the view of architectural products and their functions, the technical and economic characteristics of construction projects are as follows:

\section{1 comprehensiveness}

Building products in order to achieve certain functions and construction, in order to meet the functional requirements of the building, we must consider a variety of aspects, [2]. From the technical point of view, to the successful construction of a building, need to use computers and other tools for architectural design, the calculation of material consumption, with the owners of the building to meet the geometry of multilayer structural stability and beautiful appearance requirements. Thus, the construction technology of building products involves a number of disciplines; from an economic point of view, the construction of construction projects should take into account macroeconomic and microeconomic aspects. Of course, the construction of a building may not exert much influence on the utilization of resources and the realization of social welfare. Therefore, we should mainly consider the micro economy, rationally allocate the construction resources and maximize the benefits of the project.

\section{2 systematicness}

Construction project is a very large system, and the whole operation process will consume a lot of resources, so it is necessary to use the system concept to look at the construction project. In this case, it is also necessary to use systematic concept to treat the technical and economic evaluation of construction projects. Through the technical and economic evaluation, we can find the balance between technology and economy, and optimize the benefit of construction project.

\section{3 selective}

One of the main means of technical and economic evaluation of construction projects is to select and record them, aiming at optimizing the economic benefits and profit making space from multiple technical schemes. Compared with other products, the construction site selection, building materials, technology, technology, personnel and other factors have a serious impact on the cost of the project, although the impact of many factors, but this is the only way to select the best possible record.

\section{4 quantitative}

As the construction project is a huge system, supporting the efficient and orderly operation of this system requires a huge amount of manpower and material resources, [3]. According to modern management philosophy, human and material resources should be quantified, the only way to use the least manpower and 
material resources for the highest output, mainly reflected in the project cost, schedule and other aspects, such as shorten the construction period. Similarly, if construction materials are not quantified, waste problems such as waste of resources may arise and unnecessary construction costs will be increased. Therefore, the construction engineering technology economy has the quantitative characteristic.

\section{3. construction project technical} and economic evaluation application

In order to understand the application of technical and economic evaluation more deeply in construction projects, with a residential housing construction project, the general process of technical and economic evaluation, and established the evaluation index system of the key aspects of the brief analysis, summing up experience, to ensure the quality of technical and economic evaluation.

\section{1 application}

For construction projects, construction cost, cost, tax and profit are the basic data of technical and economic evaluation, and also the main content of economic evaluation [4]. The main body of proof of technical and economic evaluation is the subject of the project itself, not the concrete operation of the project. All the data should be scientifically and reasonably guessed and calculated in a given situation. In addition, because the construction project construction cycle is relatively long, the technical and economic evaluation should consider the time value of funds, ensure that the results are consistent with the reality, and provide a reliable basis for investment decisions. Based on the above analysis, the technical and economic evaluation of construction projects should adopt the method of selecting and recording, highlighting the primary and secondary indicators of evaluation, comprehensively weighing the importance of each index, comparing and analyzing the multiple plans. Generally speaking, the general process of technical and economic evaluation of construction projects is as follows:

Firstly, according to the actual situation of construction projects, the evaluation indexes of comparable alternatives are listed.

Second, each index is quantized and graded.

Third, based on the relative weight coefficient, according to the status, role and importance of the standard, determine the order of each evaluation index, and make clear the primary and secondary evaluation indicators.

Fourth, using mathematical methods to convert different evaluation indexes into no steel comprehensive score, the calculation is as shown in equation 3.
Formula 3: $C=\sum C i w i$

Fifth, through the formula 3 calculate the comprehensive evaluation index, and then on this basis, analysis of the pros and cons of the program. At the same time, the optimization measures are put forward to improve the project.

\section{2 application case}

3.2.1 General situation of Engineering

The design task book of a housing construction project requires that the design life of the building be 50 years, and the seismic fortification intensity is 4 degrees. There are 5 floors on the ground and 1 floors on the ground. Reinforced concrete structures are adopted. In order to avoid the errors in the final accounts of investment, the technical and economic evaluation should be carried out according to the design task book, functional requirements and other related data.

\subsection{2 technical and economic} evaluation

(1) evaluation index determination;

After comprehensive consideration, establish the technical and economic evaluation index system of residential housing construction projects. The index types mainly include social labor consumption and architectural function effect. The specific contents include: [5] index level indicators of planar space layout, plane index, physical properties, architectural art, safety, 
kitchen etc.; the two indicators have cost, comprehensive effect, flat space average living area and the average horizontal direction, and the living room number and storage facilities (planar space layout), average each building area, use the area coefficient, the average cost (index, wide plane), lighting, ventilation, heat insulation, sound insulation (physical properties), elevation effects, indoor effect (Architecture), structural safety, safety measures (safety), bathroom layout, kitchen layout (kitchen) etc. Among them, the average cost of construction area said residential area standards; the use of the area coefficient of indoor area of the total area total cost; said construction quality standard and investment calculation index, including the main cost, construction cost, cost of equipment etc.. According to the position and function of each index in the construction investment of construction project, each grade is determined.

(2) technical solutions required

Determine the corresponding weight of each index, using the formula 1, formula 2 related calculations. After calculating the weighted index of each index, the weighting index of social labor consumption index and the weighted index of building function effect index are synthesized, and the comprehensive index of the scheme is obtained. After that, compare the composite index of each scheme. Finally, combining the comprehensive analysis of the composite index, the structure is optimized to ensure the quality of the construction project. It is also necessary to make sure that there is a large profit margin, and the construction cost is strictly controlled.

The technical and economic evaluation of construction project is a method of analyzing project benefit by using scientific concepts such as economics, and strives to achieve the best unification of advanced technology and economic rationality. In the technical and economic evaluation, in addition to the actual situation of construction projects, considering the micro economic environment, we should pay attention to the following aspects of work, [6].

First, the technical and economic evaluation indicators should be more comprehensive, reflecting the basic characteristics of the program, technical characteristics, can objectively reflect the characteristics of the program, but also comparable. In general, the technical and economic evaluation indicators include three major categories: technical indicators, economic indicators and other indicators. As mentioned above.

Second, in order to ensure the scientificity and rationality of technical and economic evaluation, each index can be calculated in different ways and strategies.
Different quantitative indices are calculated using different methods. If the construction project is more complex, we can establish an economic mathematical model.

Third, the professional technical and economic evaluation of construction project is very high, and need to use some professional software, work quality and ability requirements so the related staff is high, master all kinds of technical and economic evaluation methods, from the many plans to mine valuable information, such as the scheme of basic characteristics and technical features. Lay the foundation for the subsequent optimization scheme

\section{Conclusion}

To sum up, technical and economic evaluation is an important content of project feasibility analysis. Scientific and reasonable technical and economic evaluation can not only reduce investment decision-making errors, but also reduce project costs, prevent investment risks and create greater profit margins for enterprises. Therefore, in the investment decision-making stage of construction project, the technical and economic evaluation of the project must be done well, and the feasibility, economy and technology of the construction project will be analyzed, which will provide a reliable basis for the investment decision. Of course, in addition to the construction project investment decision-making stage 
of the technical and economic evaluation, engineering design and construction stage should also be technical and economic evaluation, to control the project cost and project schedule, expanding profit margins. In a word, it is necessary to make rational use of technical and economic evaluation to improve the economic benefit of construction projects during the investment decision-making and the concrete implementation of construction projects.

\section{References}

[1], Qin Xin. On the application of technical and economic evaluation in construction projects [J]. value engineering, 2011, 30 (25): 72.

[2] Yuan Yawei. On the application of technical and economic evaluation in construction projects [J]. brand (second half), 2014, (11): $164+166$.

92-93.
[3] $\mathrm{Xu}$ Huichao, Lin Yi Chen. Economic and technical analysis of [J]. cooperation of economy and technology, in the engineering construction project in 2015 (16): 92-93.

[4], Su Ling. On the effective application of technical and economic evaluation in construction projects $[\mathrm{J}]$. transactions in economics and trade, 2015, (14): 293.

[5] Cui Cui. Discussion on the application of economic evaluation analysis in construction projects [J]. times finance, 2014, (12): 42-43.

[6] Zhang Zhang. Discussion on the application of construction technology management in construction projects $[\mathrm{J}]$. doors and windows, 2014, (03): 161+165.

[7], Bao Liang. A techno economic evaluation and analysis method under the new normal macroeconomic environment -. Taking the steel industry as an example, [J]., metallurgical economics and management, 2014, (06): 36-39.

[8] Jia Xinyao, Fang Fang. The technical and economic feasibility study China wind power construction project of [J]. management, 2014, (35): 204.

[9], Wang Hao. Sensitivity of technical and economic evaluation of construction projects [J]. science and technology information, 2014,12 (22): 222.

[10] Sun Yawei. Discussion on the sensitivity of technical and economic evaluation of construction projects $[\mathrm{J}]$. China foreign investment, 2014, (03): 132.

[11] Huang Yongzhong. The whole process control of engineering construction cost $[\mathrm{J}]$. scientific consultation (Science and technology, management), 2012, (09): 63-64. 